\title{
Monitoring Soil and Underground Water EC in a Rice Field Affected by the Great East Japan Earthquake
}

\author{
Yoshiko Muto, Eiichi Kurashima*, Kiyohito Yamamoto, Koji Harashina
}

Faculty of Agriculture, Iwate University, Morioka, Japan

\section{Email address:}

mutoy@iwate-u.ac.jp (Y. Muto), kurasima@iwate-u.ac.jp (E. Kurashima), yama3@iware-u.ac.jp (K. Yamamoto), hkoji@iwate-u.ac.jp (K. Harashina)

\section{To cite this article:}

Yoshiko Muto, Eiichi Kurashima, Kiyohito Yamamoto, Koji Harashina. Monitoring Soil and Underground Water EC in a Rice Field Affected by the Great East Japan Earthquake. International Journal of Environmental Monitoring and Analysis. Vol. 4, No. 1, 2016 , pp. 31-38.

doi: $10.11648 /$ j.ijema.20160401.16

\begin{abstract}
The Otomo rice field zone in Rikuzentakata City, Iwate Prefecture was catastrophically damaged by large-scale subsidence and the tsunami that followed the Great East Japan earthquake, which occurred on March 11th, 2011. Electrical conductivity of underground water, bulk electrical conductivity of the soil, and various meteorological elements were observed at a fixed point for eight months. The electrical conductivity of underground water fluctuated irregularly at the beginning of the observation period, temporarily reaching up to $5 \mathrm{Sm}^{-1}$ at sea level. After some time, an overall decreasing trend prevailed, and when the observations ended the conductivity of the water had dropped to $0.55 \mathrm{Sm}^{-1}$. The bulk electrical conductivity of the soil also decreased gradually, from 0.4 to $0.3 \mathrm{Sm}^{-1}$, over the eight months, which is likely linked to the interactions between rainfall and seawater intrusions. The decrease in soil conductivity has been more gradual here than in the regions affected by the tsunami following the earthquake in the Indian Ocean off Sumatra on December 26th, 2004, and in our study area it has not yet decreased to a level that would allow the resumption of rice farming. It is proposed that this difference is a result of the subsidence in Iwate Prefecture.
\end{abstract}

Keywords: East Japan Great Earthquake, Subsidence, Rice Field, Hydrological Elements, Electrical Conductivity

\section{Introduction}

The fourth largest earthquake in recorded history occurred in the Tohoku region, on the Pacific shore of Japan, on March 11th, 2011. The magnitude of this earthquake was 9.0, and its hypocenter was located $70 \mathrm{~km}$ off the Oshika peninsula, Miyagi Prefecture [1]. The tsunami caused by this earthquake exceeded $10 \mathrm{~m}$ across $530 \mathrm{~km}$ of the Tohoku coastline, and exceeded $20 \mathrm{~m}$ over $200 \mathrm{~km}$. The maximum tsunami height in the region was measured as $40.1 \mathrm{~m}$, at Ryori point in Ofunato City, Iwate Prefecture; this was also the maximum height across all of Japan [2]. The desalinization effect at farmland was monitored after the tunami in a lot of studies [e.g., 3, 4, 5].

In this study, we investigate a rice field zone in Rikuzentakata City, which received considerable damage during the 2011 tsunamis. The Otomo rice field zone in Rikuzentakata City, Iwate Prefecture is located at around $39^{\circ} \mathrm{N}$ and $142^{\circ} \mathrm{E}$, and has a total area of 120 ha, developed behind the reclamation dyke constructed along the Hirota
Bay coastline, which faces the Pacific Ocean.

The reclamation dyke in this area was constructed with a view to preventing tsunami disasters; it was begun in 1960, immediately following the Chile earthquake tsunami, and completed in 1967. The rice field area it encloses is the largest along the entire coastline of Iwate Prefecture. During the 2011 event, the reclamation dyke was completely destroyed, and the tsunami flowing from Kadonohama Bay to the east also penetrated the rice field zone, resulting in catastrophic damage from large-scale subsidence, erosion, and the large amounts of debris that the seawater carried. Following this, a temporary dyke was completed in October 2011 , the chronic flooding of the area by seawater was eased, and the removal of debris was begun.

Restoration of the area has been ongoing rapidly since June 2013, following the removal of the debris. Land improvement has almost been completed in the affected rice field zones through large-scale backfilling behind the temporary sand bag dyke, and wet rice culture recommenced in 2014.

This study focuses on the collection and analysis of data 
over eight months spanning the period of debris removal and the beginning of land restoration. During this measurement period, electrical conductivity is used as an index of salinity in the soil and subsurface water, and is considered along with various other meteorological factors. In 2015, as the reconstruction of a permanent reclamation dyke is begun, this research provides basic information for the management and prevention of salt damage in farmland, which can also be compared with the saltwater damage following the tsunami of the 2004 Sumatran earthquake [e.g., 6].

\section{Materials and Method}

\subsection{Observation Station and Subsidence of the Surrounding Area}

The single stationary measurement point for this study is located around $1 \mathrm{~km}$ southeast of the Hirota Bay coast, at $38.99392^{\circ} \mathrm{N}, 141.6933^{\circ} \mathrm{E}$. As the breakage of the water supply facilities differs across the affected rice fields and the agricultural roads around the rice fields are severed in many places, the fixed-point observation station was chosen with a consideration of the ease of communication with land owners, leaseholders, and improvement organizations, and of physical access to the point. Figure 1 shows the location of the Otomo rice field zone and the approximate site of the observation station, with a panoramic photograph taken from a nearby observatory.

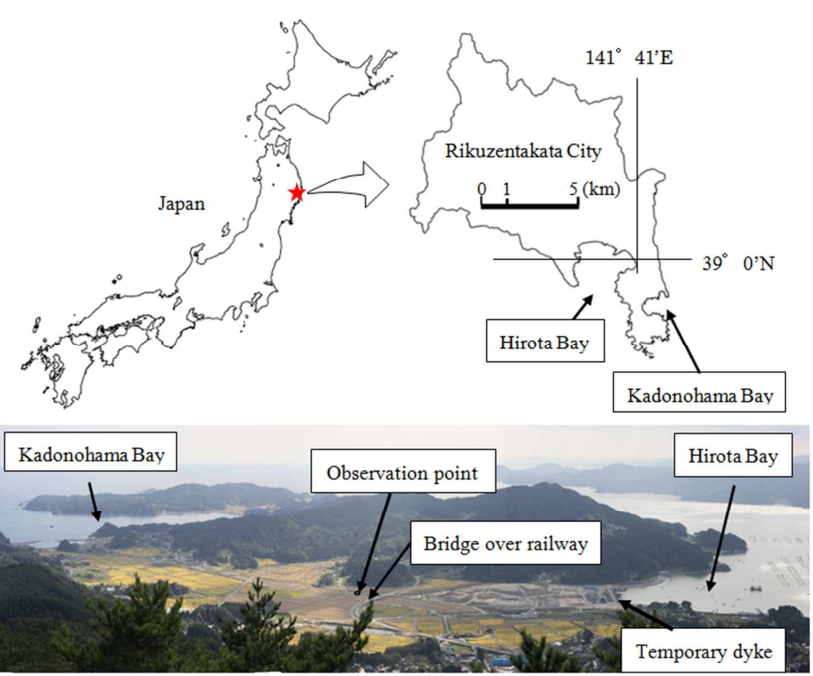

Figure 1. Location of the study area, and panoramic photograph of the Otomo rice field zone taken from a nearby observatory on October 2nd, 2014.

Figure 2(a) shows a panoramic view of the study area one month after the tsunami struck, when the rice field was flooded with seawater and was covered with a large amount of debris. Figure 2(b) shows the rice field zone two years after the tsunami, with the specific location of the observation point shown.

The horizontal distribution of subsidence around the observation point is estimated using a digital elevation model (DEM). Altitude information before the earthquake is provided by a numeric map with $50 \mathrm{~m}$ mesh, constructed from the contour lines of 1: 25,000 topographical maps, while altitudes following the earthquake are given as basic map information on a $5 \mathrm{~m}$ mesh acquired during aerial laser surveys [7]. A precise comparison of altitudes is problematic because the two datasets differ in their measurement methods and spatial resolutions, however the difference in $5 \mathrm{~m}$ mesh altitude after the earthquake that was the nearest $50 \mathrm{~m}$ mesh altitude point before the earthquake was assumed to represent the ground subsidence level.

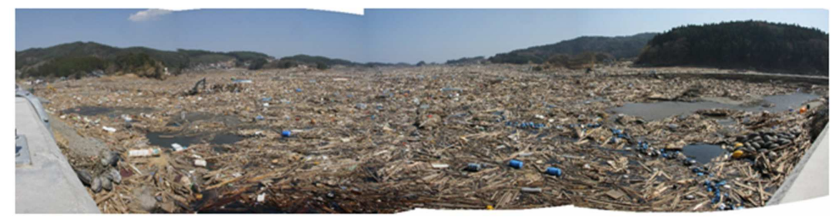

(a) April 13th, 2011

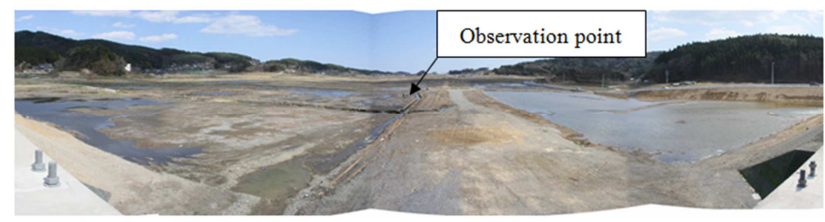

(b) April 11th, 2013

Figure 2. Photographs taken from the railway bridge that passes through the rice field zone.

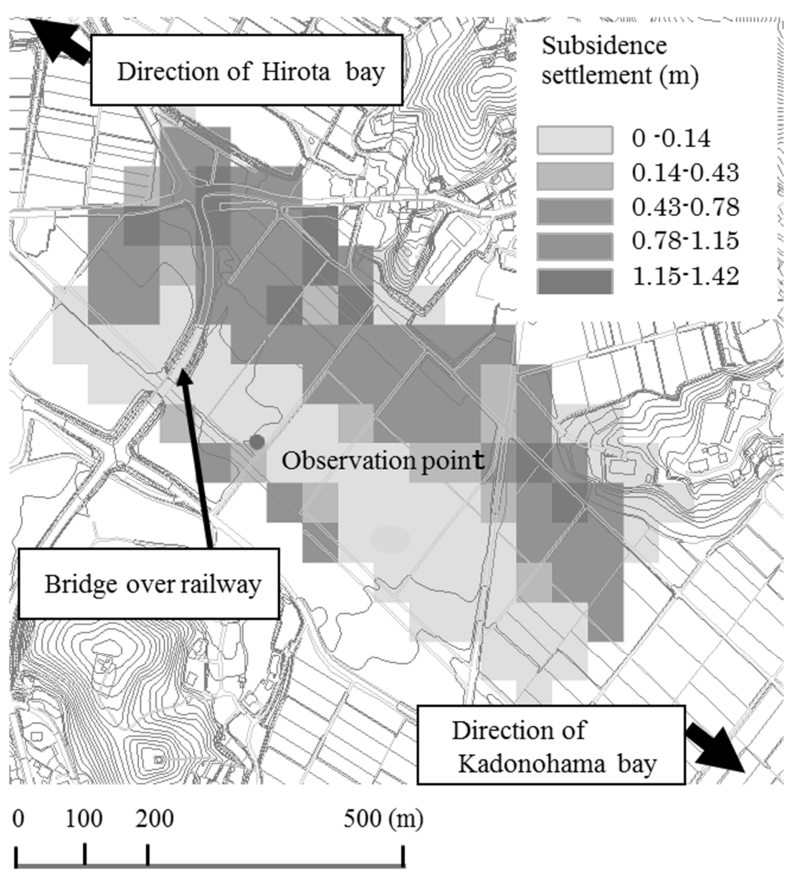

Figure 3. Approximate horizontal distribution of subsidence around the observation point following the 2011 earthquake.

Figure 3 shows the horizontal distribution of subsidence around the observation point. From this, it can be seen that the ground subsidence level is greatest to the northeast of the observation point. In support of this, the annual average difference in tide levels at Ofunato tidal observatory, $6.5 \mathrm{~km}$ from the observation point, was found to be $1.4 \mathrm{~m}$ in 2012 [8], and the maximum ground subsidence in this region is in 
accordance with the daily tidal variation.

\subsection{Observation of Electrical Conductivity and Meteorological Elements}

Figure 4 shows the sensor arrangement at the observation point. The structure in the upper part of the image is the above-mentioned bridge over the railway. A pipe was laid at a depth of $1.28 \mathrm{~m}$, in order to sample from the lower groundwater levels, and a pressure-type water gauge and electrical conductivity sensors were set up at the bottom of the pipe. Observations of the soil by relative permittivity sensors (Hydra probes) may be influenced by residual water and irregularities in the Earth's surface, and so the sensors were installed in two comparatively smooth two locations, at a separation of $20 \mathrm{~m}$.

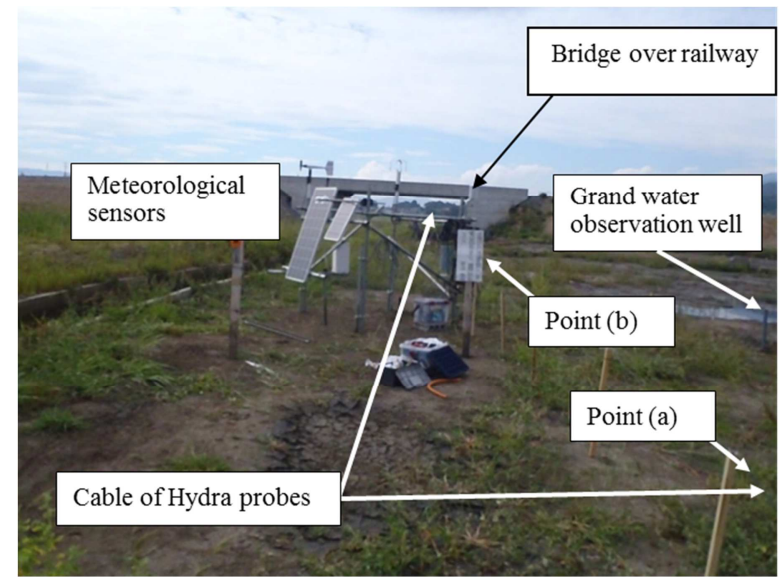

Figure 4. Arrangement of sensors at the observation station.

The ground altitudes of the two installation points, (a) and (b), are $0.51 \mathrm{~m}$ and $0.46 \mathrm{~m}$, respectively. In consideration of this difference in elevation, the Hydra probes were set up 10 $\mathrm{cm}$ and $20 \mathrm{~cm}$ below the ground level at point (a), and $5 \mathrm{~cm}$ and $15 \mathrm{~cm}$ below ground level at point (b), allowing the sensors' installation altitudes to be unified between the two points. Unfortunately, the sensors installed at depths of $20 \mathrm{~cm}$ at point (a) and $5 \mathrm{~cm}$ at point (b) failed during the early days of the observation period. Physical damage to the sensors is likely to have resulted in aberrant values, and thus their data were excluded from subsequent analyses. The particle size distributions of soils were measured. At observation (a) the soil at $10 \mathrm{~cm}$ depth comprised $66 \%$ sand, $4 \%$ clay, and $30 \%$ silt; they can be classified as sandy loam. Similarly, the soil around $15 \mathrm{~cm}$ below the surface at observation point (b) was classified as loam, with 55\% sand, $4 \%$ clay, and $41 \%$ silt. Very little vegetation cover was observed around the observation point, although some graminaceous weeds were scattered across the tsunami-stricken rice field.

In parallel with these observations, direct and reflected solar radiations, and downward and upward long wave radiations, precipitation, atmospheric pressure, and soil heat flow were measured. Additionally, in order to estimate the sensible heat flux, three-component wind velocity and sonic temperature were observed using an ultrasonic anemometer.
These sensors, with the exception of the rain gauge and the aerotonometer, were arranged on a frame $2 \mathrm{~m}$ in height and $2 \times 2 \mathrm{~m}$ in length and breadth. The rain gauge was installed in a lower position, and the aerotonometer was set up alongside the data logger. The soil heat flux sensor was installed $1 \mathrm{~cm}$ below the ground surface. The ultrasonic anemometer was connected to a CR1000 data logger (Cambell), and the measurement interval was set to $0.1 \mathrm{~s}$. Other sensors were connected to a CR3000 data logger (Cambell), with measurement intervals of $20 \mathrm{~s}$, restricted by the measurement time of the Hydra probe.

A fixed-point camera was set up on the frame with the sensors, in order to visually capture the changing conditions around the observation point. Shooting began on September 12th, but the battery of the camera set up was installed in a low position and was submerged beneath the high tide waters during Typhoon No.17 on September 30th, 2012, becoming inoperational until November 7 th. After this, measurements were made every 30 min during the daytime until April 30th; a total of 3552 scenes were captured.

Details of the observed elements and sensor models with their accuracies are shown in Table 1, although air temperature, relative humidity, wind direction and wind velocity data were not used in the following analysis. This study utilized the above-mentioned data from 236 days between September 7th, 2012 and April 30th, 2013. During the beginning of the observation period, construction of the temporary dyke was ongoing as an alternative to the older, destroyed dyke, and associated debris removal was taking place. At the end of the period, it was not possible to continue the observations, due to the beginning of land restoration.

Table 1. Models and measurement accuracy of sensors used for the observation.

\begin{tabular}{|c|c|c|c|}
\hline Observed element & Manufacture & Model & $\begin{array}{l}\text { Measurement } \\
\text { accuracy }\end{array}$ \\
\hline $\begin{array}{l}\text { Air temperature } \\
\text { Relative humidity }\end{array}$ & Vaisala & HMP155 & $\begin{array}{l} \pm 0.13^{\circ} \mathrm{C} \\
\pm 1 \%(0-90 \%) \\
\pm 1.7 \%(90-100 \%)\end{array}$ \\
\hline $\begin{array}{l}\text { Wind direction } \\
\text { Wind speed }\end{array}$ & Young & YG5103 & $\pm 3^{\circ} 0.3 \mathrm{~m} / \mathrm{s}$ \\
\hline $\begin{array}{l}\text { Atmospheric } \\
\text { pressure }\end{array}$ & Vaisala & PTB110 & $\pm 0.3 \mathrm{hPa} 20^{\circ} \mathrm{C}$ \\
\hline $\begin{array}{l}\text { 4-Components net } \\
\text { radiation }\end{array}$ & Hukseflux & NR01 & $\pm 10 \% 12 \mathrm{~h}$ totals \\
\hline Heat flow in soil & REBS & PHF-01 & $\pm 5 \%$ \\
\hline $\begin{array}{l}\text { 3-Component } \\
\text { Wind speed Sonic } \\
\text { temperature }\end{array}$ & Young & YG81000 & $\pm 0.05 \mathrm{~m} / \mathrm{s} \pm 2^{\circ} \mathrm{C}$ \\
\hline Precipitation & IKEDA & RT-5 & $\pm 3 \%$ at $20-80 \mathrm{~mm} / \mathrm{h}$ \\
\hline Grand water level & STS & ATM/N & $\pm 0.1 \%$ FS $5 \mathrm{~m}$ \\
\hline $\begin{array}{l}\text { Electric } \\
\text { conductivity } \\
\text { Temperature } \\
\text { (Grand water) }\end{array}$ & TOA DKK & CT-27112B & $\begin{array}{l} \pm 0.5 \% \text { FS } 20 \mathrm{~S} / \mathrm{m} \\
\pm 0.2^{\circ} \mathrm{C}\end{array}$ \\
\hline $\begin{array}{l}\text { Electric } \\
\text { conductivity } \\
\text { Temperature (Soil) }\end{array}$ & Stevens & Hydra probe & $\begin{array}{l} \pm 2 \% \text { or } 0.005 \mathrm{~S} / \mathrm{m} \\
\pm 0.6^{\circ} \mathrm{C}\end{array}$ \\
\hline Fix point shooting & Kadec & Eye II & \\
\hline
\end{tabular}




\subsection{History of Hydrology Factors in the Affected Rice Fields}

The amount of evaporation is one of the hydrological factors that can be estimated from the observed meteorological elements. The energy equation for the ground surface is given as

$$
\left(I_{\mathrm{s}} \downarrow-I_{\mathrm{s}} \uparrow\right)+\left(I_{\text {ir }} \downarrow-I_{\text {ir }}\right) \uparrow-I_{\mathrm{g}}=I_{\text {sen }}+I_{\text {lat }}
$$

where $I_{\mathrm{s}} \downarrow(\mathrm{Wm}-2)$ is the downwelling short wave radiation flux, $I_{\mathrm{s}} \uparrow(\mathrm{Wm}-2)$ is the upwelling short wave radiation flux, $I_{\text {ir }} \downarrow$ (Wm-2) is the downwelling long wave radiation flux, $I_{\mathrm{ir}} \uparrow(\mathrm{Wm}-2)$ is the upwelling long wave radiation flux, $I_{\text {sen }}$ $(\mathrm{Wm}-2)$ is the sensible heat flux, $I_{\text {lat }}(\mathrm{Wm}-2)$ is the latent heat flux, and $I_{\mathrm{g}}(\mathrm{Wm}-2)$ is the soil heat flux. Then, turbulent heat fluxes $I_{\text {sen }}$ can be expressed by the eddy covariance method as:

$$
I_{\text {sen }}=C_{\mathrm{p}} \rho_{\mathrm{a}} \overline{\theta^{\prime} w^{\prime}}
$$

where $C_{\mathrm{p}}(\mathrm{J} \mathrm{kg}-1 \mathrm{~K}-1)$ is the specific heat of air at a constant pressure, $\rho_{\mathrm{a}}(\mathrm{kg} \mathrm{m}-3)$ is the air density, $\theta$ is the air temperature $\left({ }^{\circ} \mathrm{C}\right), w(\mathrm{~m} \mathrm{~s}-1)$ is the vertical velocity, bar donates the average, and prime marks denote random instantaneous departures from the mean. In using Equation (2), a change in the coordinates based on wind direction, a correction of the attack-dependent error and an internal crosswind correction were applied $[9,10]$. The imbalance of the heat budget between the sum of sensible heat and latent heat obtained by the eddy covariance method and other observed elements has been noted, and it has been shown that the ratio of right-hand values to left-hand values of Equation (1) is 0.84 over an average of 50 samples [11]. Therefore, there is a possibility that this represents a margin of error in the amount of evaporation estimated by this method. However, it is difficult to unambiguously identify the causes and patterns of this error from the limited observations of this study.

On the basis of the fixed-point photography, it was estimated that the study area was covered by snow for 11 days, from January 9th to February 26th, 2013. During this time, it is necessary to consider the changes in temperature and phase within the snow cover. However, it was assumed that the amount of evaporation over these 11 days was negligible, on the basis of previous reports that found that evaporation from snow surfaces during the melt season was very small [12].

\subsection{Corrections of Electrical Conductivity of Underground Water and Bulk Electrical Conductivity of Soil}

The measurements of electric conductivity of underground water are based on the 2-AC bipolar method. Owing to the fact that the electrical conductivity of solutions shows considerable temperature dependence $\left(2 \% / 1^{\circ} \mathrm{C}\right)$, the electrical conductivity of underground water was converted to its corresponding value based on a temperature of $25^{\circ} \mathrm{C}$. The temperature-corrected electrical conductivity at $25^{\circ} \mathrm{C}, E C_{\mathrm{w} 25}$
$(\mathrm{S} \mathrm{m}-1)$ can therefore be expressed as:

$$
E C_{\mathrm{w} 25}=\frac{E C_{\mathrm{w} t}}{[1+0.02(t-25)]}
$$

where $E C_{\mathrm{w} t}(\mathrm{~S} \mathrm{~m}-1)$ is the electrical conductivity of underground water at $t\left({ }^{\circ} \mathrm{C}\right)$.

The Hydra Probe is a sensor that measures the permittivity and the temperature of the soil, and electrical conductivity EC $(\mathrm{S} \mathrm{m}-1)$ is expressed as

$$
E C=2 \pi f \varepsilon_{0} \varepsilon_{\mathrm{r}}^{\prime \prime}
$$

where $\varepsilon_{\mathrm{r}}^{\prime \prime}$ is the imaginary component of the relative complex permittivity, $f$ is the frequency $(50 \mathrm{MHz}$ for the Hydra Probe), and $\varepsilon_{0}$ is the dielectric constant in a vacuum (8.854 $\times 10-12 \mathrm{~F} \mathrm{~m}-1)$. As the relative permittivity depends on the temperature, the relative permittivity was converted to its corresponding value based on a temperature of $25^{\circ} \mathrm{C}$. The temperature-corrected dielectric permittivity $\varepsilon_{\mathrm{r} 25}^{\prime \prime}$ is therefore expressed as [13]:

$$
\varepsilon_{\mathrm{r} 25}^{\prime \prime}=\frac{\varepsilon_{\mathrm{r}}^{\prime \prime} \times 1.0755}{0.693+0.0153 \times T}
$$

where $T\left({ }^{\circ} \mathrm{C}\right)$ is the soil temperature. In this study, we obtain the electrical conductivity of bulk soil $E C_{\mathrm{a}}$ by substituting $\varepsilon_{\mathrm{r} 25}^{\prime \prime}$ into equation (4).

\section{Results and Discussion}

\subsection{Hydrological Factors}

Figure 5 shows the daily precipitation and estimated daily evaporation. The total precipitation over the study period was $692 \mathrm{~mm}$, while evaporation was $336 \mathrm{~mm}$. Observations of antecedent precipitation at the AMeDAS (Automated Meteorological Data Acquisition System) point [14], nearly 8 $\mathrm{km}$ from the observation point of this study, totaled $1070 \mathrm{~mm}$ between October 2011, when the temporary dyke was completed, to August 2012 when our observations began (during the debris removal work). Flooding from the inflow of rain and seawater that originated around the demolished reclamation dyke and subsided areas is frequently seen, representing a particular hydrological phenomenon of the area around the observation point. It is difficult to quantify the inflow of such water, and therefore its extent is demonstrated by the scenes captured by fixed- point photography. Figure 6 shows the flooded area compared with dry conditions (Figure $6 \mathrm{a})$. Figure $6 \mathrm{~b}$ illustrates the flooding associated with Typhoon No.17, which was linked to a barometric depression of 992 $\mathrm{hPa}$ and an associated sea level rise. Figure $6 \mathrm{c}$ shows a flooding event believed to be derived from rainfall, as it is correlated with a continuous rainfall event of $43.5 \mathrm{~mm}$. In total, 181 of the 3552 pictures captured during the fixed-point photography reveal flooding during the observation period. 
Figure 7 illustrates the hourly groundwater level. The water table rose from 0.25 to $0.53 \mathrm{~m}$ between $28^{\text {th }}$ and $29^{\text {th }}$ October 2012 , in combination with a total precipitation of $79 \mathrm{~mm}$ during this period. Additionally, it showed a gradual decrease during the low-rainfall period from the middle of December to the beginning of April. A periodic change in groundwater level was also seen under the influence of rainfall events, as noted above. Figure 8 shows a periodic analysis of $512 \mathrm{~h}$ $\left(512=2^{9}\right)$ from 1 st to 22 nd of October and November 2012, using the fast Fourier transform algorithm. Twelve-hour and 24-hour cycles, as well as variations in sea level, were identified as amplitudes although the signals derived from rainfall events were also confirmed.
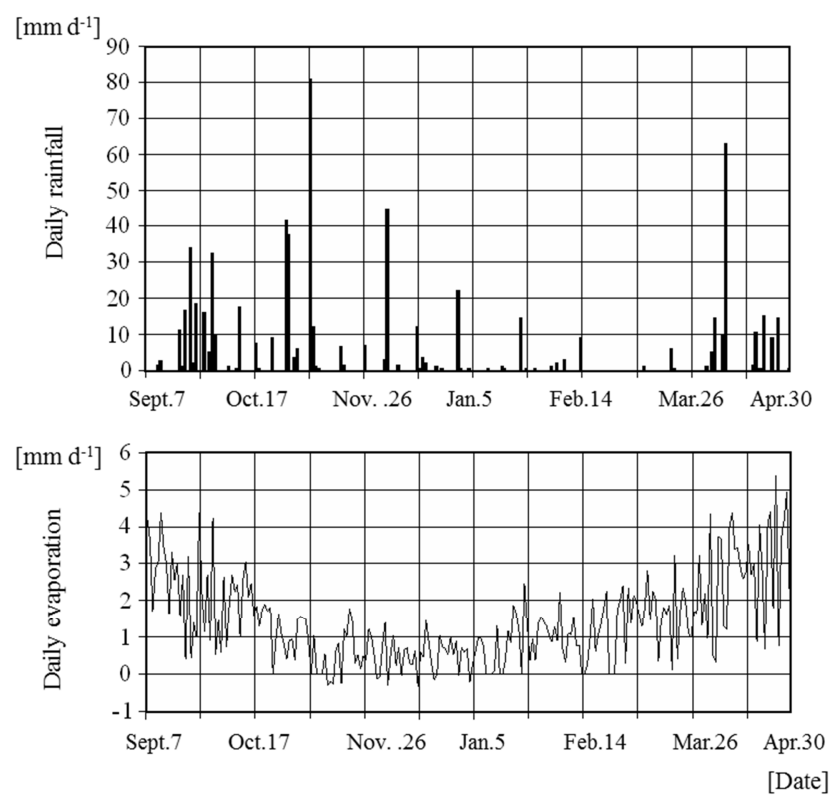

Figure 5. Observed daily rainfall and estimated daily evaporation during the study period.

Figure 9 shows the time varying correlation coefficient between the tidal level at the Ofunato tidal observatory [8] and the groundwater levels during a period of seven days with no rainfall from 19th to 25th November. This demonstrates that the temporal difference between tidal level and groundwater level variations was almost three hours, with an average correlation coefficient of 0.54 , implying that changes in groundwater level are closely synchronized with tidal levels. Hilton et al. studied the distributions of salt water and fresh water in the groundwater of the Florida peninsula in the United States, and found that the diffusion range of saltwater inland from the coast was around $0.6 \mathrm{~km}$ [15]. It should also be noted that

Rikuzentakata was not one of the 21 saltwater intrusion regions identified across the Japanese Islands by Hamaguchi et al. [16]. Although these studies represent only circumstantial evidence, it seems that the saltwater intrusion in our study region, which can be attributed to the subsidence and the fully-destroyed reclamation dyke, caused a periodic change in the groundwater level at our observation station, around $1 \mathrm{~km}$ away from the coastline.

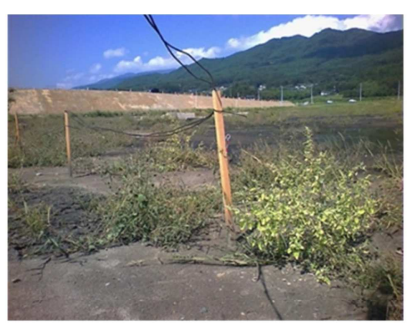

(a) Dry condition(12:00 Sept. $\left.14^{\text {th }}, 2012\right)$

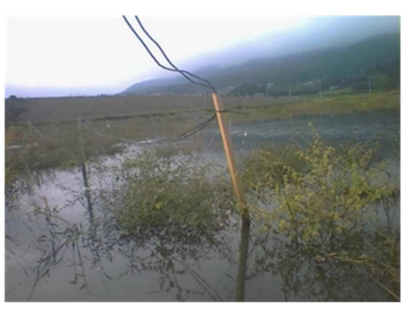

(b) During the approach of Typhoon No.17 (16:30 Sept. $\left.30^{\text {th }}, 2012\right)$

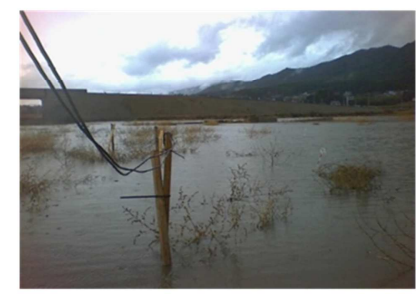

(c) Immediately following rainfall (12:00 Dec. $\left.4^{\text {th }}, 2012\right)$

Figure 6. Flooding at the observation station.

[m]

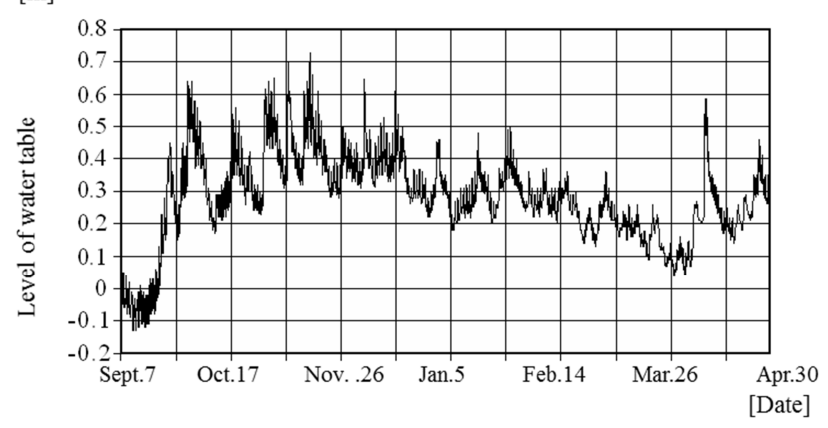

Figure 7. Hourly water table levels.

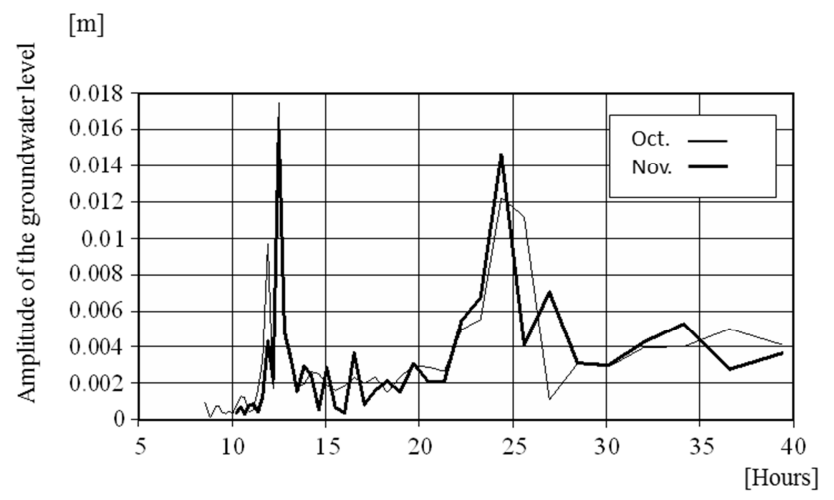

Figure 8. Periodic analyses of groundwater level during October and November 2012, by fast Fourier transformation. 


\subsection{Changes in Electrical Conductivity}

Kume et al. [17] suggested that the salinity of the underground water of permeable farmland in the Nagapattinam district, India, which was affected by the tsunami caused by the earthquake in the Indian.

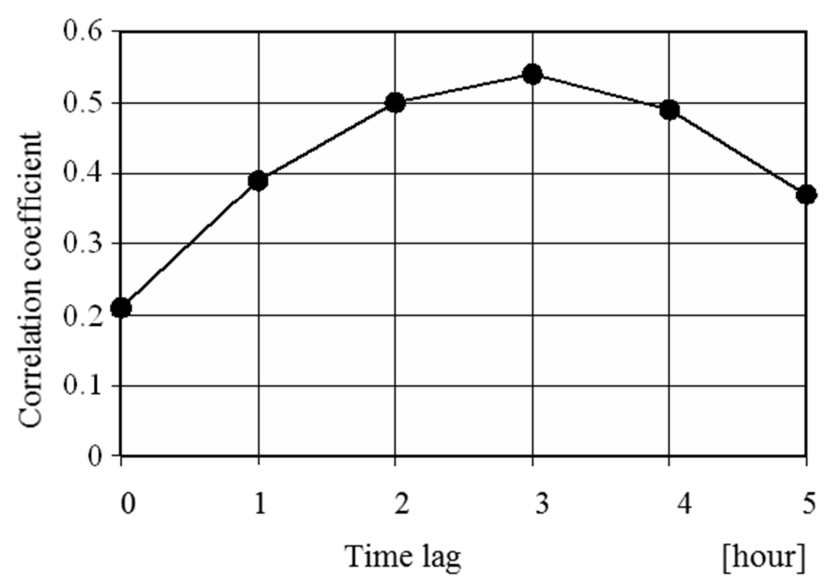

Figure 9. Correlation coefficients of sea level and groundwater level during a no-rainfall period.
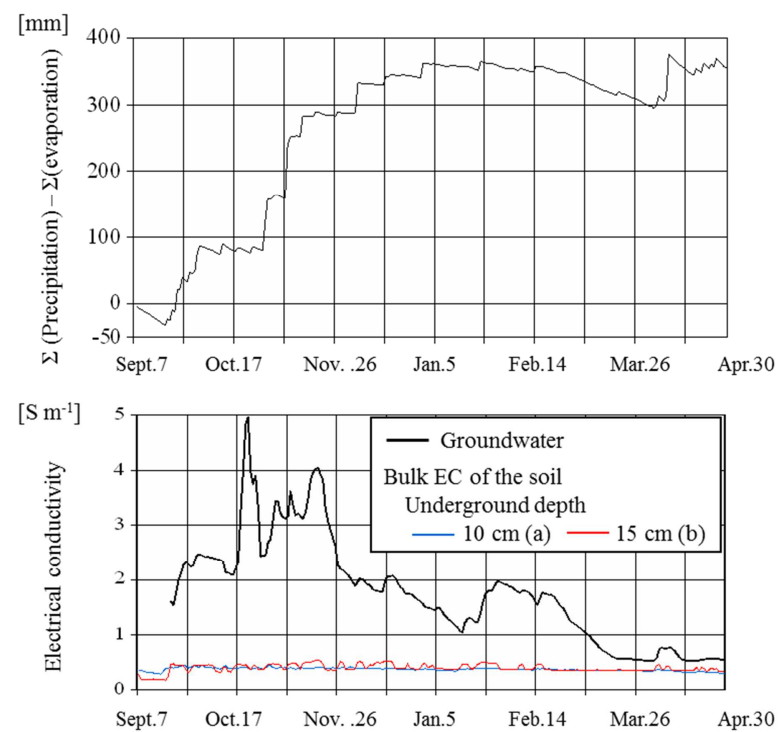

Figure 10. Daily mean electrical conductivity of soil and underground water, and daily change in accumulated input (precipitation) minus output (evaporation).

Ocean off Sumatra on December 26, 2004, had returned to pre-tsunami levels by the monsoon rainfall of 2006 . Illangasekare, et al. [18] estimated that the salinity of coastal aquifers in Sri Lanka, where seawater mixed with ground water via open wells during the tsunami of the same earthquake, would be decreased by the monsoon climate. They also suggested that evapotranspiration during the dry season was a major factor contributing to the increase in salinity of underground water in the same region.

Figure 10 shows the daily mean electrical conductivity of underground water, in addition to the integrated value of precipitation minus evapotranspiration. No clear relationship can be identified between the changes in electrical conductivity and the relative water supply, as both have varied irregularly since the beginning of the observation period. However, it can be suggested that an increase in precipitation will increase the groundwater level, during which salt water mixing may be temporarily facilitated. It can be seen that electric conductivity reached $5 \mathrm{Sm}-1$ on October 21 . This high value was possibly induced by a concentration of seawater in the region. Subsequently, after some irregular variations, the conductivity began to gradually decrease after November 19th. The change in the electrical conductivity of underground water at a point at which seawater often infiltrated indicates that dilution by fresh water was generally superior to the supply of salt water, although the variations are not typically temporally distinct. Finally, the conductivity of the underground water seemed to converge on the bulk electrical conductivity of the soil, as described below. The daily mean bulk soil electrical conductivity $E C_{\mathrm{a}}$ remained around 0.4 $\mathrm{Sm}-1$ at both points (a, $10 \mathrm{~cm}$ below the ground, and b, $15 \mathrm{~cm}$ below the ground ) from the beginning of the observation period to the end of December, after which it decreased, to around $0.3 \mathrm{Sm}-1$ when the observation ended (Figure 10). The electrical conductivity of a saturation extract $\left(E C_{\mathrm{e}}\right)$ is the best index for the salinity resistance of plants [e.g.19]. Rhoades et al. [20] presented the regression expressions between $E C_{\mathrm{e}}$ $\left(\mathrm{S} \mathrm{m}^{-1}\right)$ and $E C_{\mathrm{a}}\left(\mathrm{S} \mathrm{m}^{-1}\right)$ for different soils at their field-capacity water contents, and $E C_{\mathrm{e}}$ of the loam can be expressed as

$$
E C_{\mathrm{e}}=5.47 \times E C_{\mathrm{a}}-0.047
$$

$E C_{\mathrm{e}}$ of the studied area is estimated to be at least $1.6 \mathrm{~S} \mathrm{~m}-1$ on the basis of this equation. Additionally, the approximate relationship between the relative yield of rice plants, $Y_{\mathrm{r}}(\%)$, and $E C_{\mathrm{e}}$ can be expressed as [21]:

$$
Y_{\mathrm{r}}=100-\left[12 \times\left(10 \times E C_{\mathrm{e}}-3\right)\right]
$$

Thus, a rice harvest cannot be expected according to the calculations using these equations, even for $E C_{\mathrm{a}}=0.3$.

Two monsoon seasons have passed since the Asian tsunami hit the region around the Indian Ocean, and it has been shown that the electrical conductivity of the soil in these areas has decreased dramatically, even in the farmland of the Andaman Islands where sea water sometimes intrudes at high tides, especially during new moons and full moons [6]. It has also been shown that the electrical conductivity of farmland in the Nagapattinam District in southern India, affected by the same tsunami, has decreased to pre-tsunami levels as a result of the accumulation of rainfall [22]. It is clear that the decrease in the electrical conductivity of soil at the observation point is slower than that found in previous studies [6, 17, 18, 22], and it is suggested that the difference is due to the relative presence or absence of ground subsidence.

It can be concluded that land restoration by a large-scale filling is an appropriate method, based on the present electrical 
conductivity of the soil. Furthermore, it will be necessary to continue monitoring the salinity of underground water and soil in this area in order to fully track and manage the regeneration of this region.

\section{Conclusions}

This study focused on the Otomo rice field zone in Rikuzentakada City, Iwate Prefecture, which experienced considerable damage as a result of the subsidence and the tsunami following the Great East Japan Earthquake in 2011. A fixed-point observation station was set up to enable long-term observation of meteorological elements, as well as the electrical conductivity of underground water and soil. These observations were begun in September 2012 following the removal of the tsunami debris, and continued until April 2013 when restoration construction was begun.

The observation point $\left(38.99392^{\circ} \mathrm{N}, 141.6933^{\circ} \mathrm{E}\right)$ is located $1 \mathrm{~km}$ from the coast, and was chosen on the basis of ease of access and communication with the landowners. It was shown that non-uniform subsidence of up to $1.4 \mathrm{~m}$ had occurred around the observation point. This subsidence represented a remote cause of flooding, and floods due to rainfall events were also frequently observed around the observation point. It was also shown that the groundwater level covaried with the tide, and exhibited periodic changes.

Rainfall and evaporation were compared with the electrical conductivity of underground water over the entire eight-month observation period. Although a distinct relationship cannot be identified between these factors, the electrical conductivity of underground water showed a gradual decrease after undergoing a period of irregular change.

The bulk electrical conductivity of the soil did not show any major changes, and a gradual decrease was observed over the entire observation period. It was calculated that a harvest of rice could not be expected, even though the bulk electrical conductivity had decreased to $0.3 \mathrm{Sm}^{-1}$. These results contrasted with previous reports of lands affected by the 2004 Asian tsunami, in which the electrical conductivity was significantly decreased by rain infiltration. It is therefore supposed that the difference between these situations is due to the subsidence in our study area.

On the basis of these soil conditions, land restoration through large-scale earth filling appears to be an appropriate approach.

\section{Acknowledgements}

Part of this study was funded by the Japanese River Improvement Fund in 2013 (code: 25-1215-005).

\section{References}

[1] US Geological Survey (2011) Magnitude 9.0 - NEAR THE EAST COAST OF HONSHU, JAPAN. http://earthquake.usgs.gov/earthquakes/eqinthenews/2011/usc 0001xgp/. Accessed 3 May 2013.
[2] The 2011 Tohoku Earthquake Tsunami Joint Survey (TTJS) Group (2011) The 2011 off the Pacific coast of Tohoku Earthquake Tsunami Information.

[3] Chibai K, Kanmuri H, Kati T (2012) Desalinization technique for tunami-hit farmland by infiltration of rain and discharge from underdrain. J. Jpn. Soc. Soil Phys. 121: 29-33 (Japanese).

[4] Yamamoto K, Kobayashi A, Harashina K, Kurashima E, Muto Y, Tukada Y (2015) Change in salinity concentration measured by electromagnetic survey in the paddy fields damaged from tsunami. Water, Land and Environ. Eng. 83: 671-676 (Japanese).

[5] Yamamoto K, Kobayashi A, Muto Y, Kurashima E, Harashina $\mathrm{K}$, Tukada Y (2015) Change in salinity concentration for irrigation tank embankment submerged in sea water due to the 2011 tohoku tunami. IDRE Jornal 299: I_165-I_175 (Japanese with English summary).

[6] Raja R, Chaudhuri SG., Ravisankar N, Swarnam TP, Jayakumar V, Srivastava RC (2009) Salinity status of tsunami-affected soil and water resources of South Andaman, India. Curr Sci 96: 152-156.

[7] Geospatial Information Authority of Japan (2012) Maps \& Geospatial Information. http://www.gsi.go.jp/ENGLISH/page_e30031.html. Accessed 8 Oct. 2012.

[8] Japan Meteorological Agency (2014a) Tidal observation data set.

http://www.data.jma.go.jp/gmd/kaiyou/db/tide/genbo/index.ph p. Accessed 30 May 2014.

[9] Gash J. H. C. Dolman A. J. (2003) Sonic anemometer (co)sine response and flux measurement: I. The potential for (co)sine error to affect sonic anemometer-based flux measurements. Agric For Meteorol 119: 195-207. doi: 10.1016/S0168-1923(03)00137-0.

[10] Schotanus P, Nieuwstadt FTM, deBruin HAR (1983) Temperature measurement with a sonic anemometer and its application to heat and moisture fluxes. Boundary Layer Meteorol 26: 81-93.

[11] Wilson K, Goldstein A, Falge E, Aubinet E, Baldocchi D, Berbigier P, Bernhofer C, Ceulemans R, Dolman H, Field C, Grelle A, Ibrom A, Law BE, Kowalski A, Meyers T, Moncrieff J, Monson R, Oechel W, Tenhunen J, Valentini R, Verma S (2002) Energy balance closure at FLUXNET sites. Agric For Meteorol 113: 223-243, doi: 10.1016/S0168-1923(02)00109-0.

[12] Kojima K (1967) A field experiment on the influence of evaporation of snow upon snow melt. Low temperature science Series A, Physical sciences 25: 119-126 (Japanese with English summary, 125).

[13] Bellingham K (2007) The Stevens Hydra Probe inorganic soil calibrations. Stevens Water Monitoring Systems Inc: 1-5. $\mathrm{http}: / / \mathrm{www}$. stevenswater.com/catalog/products/soil sensors/d atasheet $/$ The $\% 20$ Stevens $\% 20$ Hydra $\% 20$ Probe $\% 20$ Inorganic $\%$ 20Soil\%20Calibrations.pdf. Accessed 6 May 2015.

[14] Japan Meteorological Agency (2014b) Climate of Japan. http://www.data.jma.go.jp/obd/stats/data/en/index.html. Accessed 30 May 2014. 
[15] Hilton H, Cooper J, Francis AK, Harold RH, Robert EC (1964) Relation of salt water to fresh ground water. Sea water in coastal aquifers. USA government printing Office. Washington DC USA: 1-11. http://pubs.er.usgs.gov/. Accessed 10 June 2015.

[16] Hamaguchi T, Kamal A, Sumi T (2013) Fundamental study on development of horizontal seawater intrusion model in coastal aquifer. Kyoto University Disaster Prevention Research Institute Annuals 56B: 585-589 (Japanese with English summary, 585).

[17] Kume T, Umetsu C, Palanisami K (2009) Impact of the December 2004 tsunami on soil, groundwater and vegetation in the Nagapattinam district, India. J Environ Manage 90: 31473154. doi: 10.1016/j.jenvman.2009.05.027.

[18] Illangasekare T, Scott WT, Clement TP, Villholth KG, Perera APGR. L, Obeysekera J, Gunatilaka A, Panabokke C, Hyndman DW, Cunningham K, Kaluarachchi JJ, Yeh WW-G, van Genuchten MT, Jensen K (2006) Impacts of the 2004 tsunami on groundwater resources in Sri Lanka. Water Resour Res 42: W05201. doi: 10.1029/2006WR004876.
[19] US Salinity Laboratory Staff (1954) Diagnosis and improvement of saline and alkali soils, Agriculture. Handbook 60; U. S. Government Printing Office: Washington D. C., USA, pp 55-68.

[20] Rhoades JD, Chanduvi F, Lesch S (1999) Soil salinity assessment method and interpretation of electrical conductivity measurements. FAO Irrigation and Drainage Papers 57: 15-62.

[21] Dobermann A, Fairhurst T (2000) Rice: Nutrient disorders \& nutrient management. Handbook series. Potash \& Phosphate Institute (PPI), Potash \& Phosphate Institute of Canada (PPIC) and International Rice Research Institute. 191p.

[22] Chandrasekharan H, Sarangi A, Nagarajan M, Singh VP, Rao DMP, Stalin P, Natarajan K, Chandrasekaran B, Anbazhagan S (2008) Variability of soil-water quality due to Tsunami-2004 in the coastal belt of Nagapattinam district. J Environ Manage 89: 63-72. doi: 10.1016/j.jenvman.2007.01.051. 